\title{
THE VALUE OF EXPERIENCE IN LEGAL COMPETENCE
}

\author{
By Avrom Sherr \\ Woolf Professor of Legal Education \\ Institute of Advanced Legal Studies, University of London
}

This article considers the importance of experience in providing competence for legal practitioners in the skill of client interviewing and counselling. Previous research carried out within a laboratory setting ${ }^{1}$ developed a system of assessment, which is used in this research to monitor the work of a number of lawyers across a range of experience carrying out real client interviews in their own offices. It is then possible to compare the performance of experienced practitioners against the inexperienced.

The "real life" lawyers assessed in this study provide much richer contextual detail than in laboratory settings. The nature of the offices, the work carried out, the details of reception area and age and social background of lawyers and clients can be compared and all of these measured against the competence of the lawyers shown.

The value of experience in the practice of legal skills can then be considered and compared with the likely value of directed training methods such as those to be used in the new Law Society Finals, the "Legal Practice Course".

\section{Learning By Experience}

The new system of training for solicitors suggests a change of approach which will involve the teaching of lawyering skills at the postgraduate level. This will be followed up by a Professional Skills Course in articles and a programme of compulsory continuing legal education intended to provide law and skills 'top-up' throughout a practitioner's career. ${ }^{2}$ For most lawyers, however, formal training in legal skills such as interviewing has not existed and any ability or knowledge has been picked up on the job through the experience of watching others, or carrying out the work itself. Indeed, a strong presumption has existed among many practitioners that experience is the only way of learning such skills. This study is intended to examine the effectiveness of the method of learning by experience alone within the context of lawyer-client interviewing, and to note where training might best be injected into this system. 
The notion that knowledge and practice can be learned from experience even within a controlled educational environment gained special significance during the 1960s and 1970s as a part of the movement against formalism in education. Legal education in North America, where postgraduate students had been prepared by the regime of undergraduate education, provided fertile ground for the seeds of change. "Clinical legal education" was assisted by strong judicial opinion that legal ethics could only be learned within the culture of practice and experience ${ }^{3}$. This view was supported by the Ford Foundation whose Council for Legal Education in Professional Responsibility funded the first clinical courses in nearly all law schools in the United States ${ }^{4}$. The intention of such courses was partly to provide the practical legal education which was seen as lacking in the non-apprentice based system for legal qualification in North America. It was also seen as a method of transmission of knowledge and ideas which compared favourably with the more static view of traditional case method legal education; even that undertaken by socratic dialogue.

Clinical teachers were democratic and anti-authoritarian. The work was personal and took account of clients' and students' needs and issues of "social justice" rather than the public, forensic atmosphere of the socratic lecture room. New generations of law students were introduced to the perspectives, problems and skills of practice through the experiential learning approach of clinical legal education. It provided a focus for revaluing the traditional legal process and re-assessing its worth and effectiveness.

The importance of experiential learning systems was emphasised at this period but has a long history noted recently by Macfarlane. ${ }^{5}$ She shows how Dewey's seminal work on "Experience and Education" ${ }^{6}$ built on the work of earlier natural law philosophers such as David Hume ${ }^{7}$ in arguing that knowledge was not static but was something seen through the perspective of each individual. Each person's experience and perception provided the link between the different elements of knowledge which could be picked up either from formal material such as books and teaching or from experience itself, "the school of hard knocks". Knowledge distilled and encapsulated within the covers of books might itself be a mode of entering or appreciating the experience of others but could not provide the keenness of personal perception. Philosophers of the more definitive scientific world expressed the view that "science now begins and ends with problems". ${ }^{8}$ Developmental psychologists such as Piaget linked cognitive psychology theory with the development of the child showing how children began to interpret experience through nascent theories or "schema" which gave them hypothetical bases for determining and

Chief J. Warren Burger "The Role of the Law School in the Teaching of Legal Ethics and Professional Responsibility" 198029 Cleveland State Law Review 377.

Meltsner and Schrag "Report from a CLEPR Colony" 76 Colum. Law Rev.581; "Scenes from a Clinic" 1978, Univ. of Pennsylvania Law Rev.1.

See Julie Macfarlane "Look Before you Leap: Knowledge and Learning in Legal Skills Education" (1992) 19 Law and Soc. Rev. 3015 and see Cyril Houle "Deep Traditions of Experiential Learning" in "Experiential Learning" Morris Keaton and Pamela Tate eds. p.23-24 (San Francisco, 1978).

New York 1938

"Dialogues on Natural Religion" 1779 and Macfarlane see 5 above.

Popper K. "The Logic of Scientific Discovery" 1959 as quoted by Macfarlane. 
understanding the world around them. ${ }^{9}$ The work of Jerome Bruner placed these ideas more firmly into the context of experience-based learning as a mode of education. ${ }^{10}$ Education was seen as a "process not a product". Learning was not a simple consumption of knowledge, but the learner was "a goal-oriented intelligence who constructs knowledge rather than absorbs it". ${ }^{11}$

Kolb and Fry show a four stage process through which experiential learning occurs. ${ }^{12}$ From being involved in a concrete experience students must then reflect on what occurred. They then formulate an abstract generalisation which in the fourth stage is tested against further concrete experience and thus a schema is formed, tried and tested. Experience is therefore "the dialectic between concrete experimentation on the one hand and abstract conceptualisation on the other. ${ }^{13}$

\section{$\underline{\text { Experience Alone? }}$}

It should be noted that none of the theories records experience alone as being the great educator. All theories suggest a major interactive process between the existing knowledge, the experience and the student assimilating the knowledge. This dynamic process involves a constant cycle of review and monitoring of experience and comparison between previous knowledge and each new occurrence. In the same way as formal education was unsatisfactory because it did not consider sufficiently the reactions of the taught as opposed to the methods of the teacher, so experiential learning which was accepted in a static manner would also suffer.

The importance of experience was its richness, its diversity and its perceptual effects on the individual learner. No theory suggested that the learning could occur entirely subconsciously and without effort. Vygotsky shows that knowledge must be integrated into experience via social behaviours at school, at home or with peer groups. A "zone of proximal development" is necessary in which a peer, teacher or colleague is involved in order for each individual to achieve to the extent of their abilities. ${ }^{14}$ In other words, within the educational sphere, the literature suggests that it is necessary for either the individual student or another person involved in the process to adopt an active "teaching" role for the process of learning by experience to work.

This suggests a dynamic approach to knowledge. Students need to move from 'declarative knowledge' (the formal ability to state propositions and concepts) through 'procedural knowledge' (an ability to organise, recall and rationalise declarative knowledge) and then on to

Jean Piaget "The Origins of Intelligent Children" 1952 and Unzer, E. "Cognitive Development: Learning and the Mechanisms for Change" in "Development In Learning and Assessment", Murphy P. and Moon B. 1989.

See e.g. Bruner J. "Towards a Theory of Instruction" 1966 "The Process of Education" Harvard University Press, 1960, and "A Study of Thinking" (1956).

11 Lesgold and Glaser eds. "Foundations for a Psychology of Education " 1989, Hillsdale, New Jersey Preface x. I am indebted to Richard Moorhead for preliminary research into educational psychology and clinical legal education. He also made kind comments on the remainder of the manuscript.

12 David A. Kolb and Ronald Fry, "Towards An Applied Theory Of Experiential Learning" in "Theories Of Group Processes" Carrie L. Cooper ed. p.33 (New York 1975).

13 David Kolb "Experiential Learning: Experience As the Source of Learning and Development" 1984.

$14 \quad$ L.S. Vygotsky "Mind in Society" 1978. 
'expertise' (sophisticated articulations of procedural knowledge in increasingly sophisticated contexts). ${ }^{15}$ The learning context is itself said to be important in fostering such dynamism and educators have a key role in developing real perceptions of experience. "If in a particular type of problem the learner's first experience leads to perceiving symptoms or other cues as individual units, then this tendency persists, whereas if during early experience attention to patterns is rewarded, then the higher order units come to dominate performance." ${ }^{16}$

Voss reviews two pieces of research looking at the value of experience. The problem-solving ability of experts in Soviet domestic policy showed markedly more sophisticated approaches than two groups of undergraduates, one about to begin a course and the others who had just completed a course on the subject area. Students, who had completed the course and had the necessary declarative knowledge, had failed yet to develop the procedural knowledge necessary to become problem solvers. Training within the isolated context of the world of learning was not sufficient for transportation of the ideas learned, into the real world. Experience, however, was seen to be able to provide the necessary effect. ${ }^{17}$

Similar results were shown in a study of diagnostic reasoning comparing expert, trainee and student medics. The experts demonstrated a better knowledge of the disease and "superior skill in interpreting the cues given by the patient; errors made by the less experienced individuals were primarily attributable to an inappropriate interpretation of cues." ${ }^{18}$ The crucial difference between the expert and novice was not in substantive knowledge but the ability to see what they were looking for and understand its significance in the uncontrolled and interactive environment of "real life". A doctor unable to interpret patient cues might render substantive knowledge useless. An inexperienced young lawyer presented with a client may therefore be less likely to recognise the nature of the issues involved however well trained in substantive law. ${ }^{19}$

But placed against the background of experiments such as these is also the considerable view expressed that experience by itself may not necessarily be beneficial. ${ }^{20}$ If it is not clear what should be learned from the mass of incoming information deriving from the world of reality, inaccurate or wrong messages can be learned. Learning needs some distance, and the keenness of individual perception mixes personal emotion with any ability for intellectual analysis. Learners need to be taught and encouraged how to use experience as an instructional tool and so develop their own systems for learning from experience in later life. ${ }^{21}$

\footnotetext{
$15 \quad$ See Estes in Lesgold and Glaser op.cit pp.6-26.

$16 \quad$ Estes op.cit p.20.

$17 \quad$ Voss op.cit p.270.

$18 \quad$ Voss op.cit p.283

Similar findings of failure to interview clients effectively have been found recently in legal settings. See e.g. Sherr A. "Lawyers and Clients: The First Meeting" 198649 Modern Law Review 333 and Economides K. and Smallcombe G. "Preparatory Skills Training For Trainee Solicitors" Law Society RPPU 1991. 
In the unstructured environment of the real world, "individuals are often called upon to provide their own goals, means, spurs to action or persistence, and rewards for progress". ${ }^{22}$ Problems in post-educational experience become more complex and less well-defined, so that even identifying when a problem exists may be a fundamental skill in itself.

\section{Clinical Legal Education and Educational Goals}

Clinical legal education is an important example of an open context in which the lines of demarcation between training and experience are removed, therefore increasing the confidence necessary for promoting "learning goals" as opposed to "performance goals"23 and explaining how to learn from experience.

Bellow describes how:

"experience produces a qualitative change in the mode and content of knowing, which cannot be replicated by the transmission of information or the discussion of cases...in the classroom. The ways in which legal concepts and ideas are understood after they have been used... "feels" different in a sense that is not fully explained by the fact that they are more readily remembered." 24

This suggests the importance of the "affective" and "attitude shaping" nature of moral development argued for clinical legal education, as well as its intellectual value. ${ }^{25}$

Barnhizer observes that clinical education places students in role as lawyers of real clients and allows them to consider their emotional and moral reactions as well as the intellectual response. ${ }^{26}$ Barnhizer points out that :

"The experiences of employment and entry into the legal profession which confront students immediately upon graduation from law school create intensely significant economic, political and peer pressures to conform to prevailing standards... It is difficult enough to withstand these forces if the individual has already developed a clear and strong understanding of his personal sense of responsibility and fundamental values. If the individual has not developed a workable system of responsibility, however, it will be virtually impossible to transcend experiences." 27

\footnotetext{
$22 \quad$ Dwek in Lesgold and Glaser op.cit p.126.

23 See Dwek in Lesgold and Glaser p.96.

24 Bellow "On Teaching The Teachers: Some Preliminary Reflections on Clinical Education as Methodology" p.382.

25 See e.g. Stone, "Legal Education On The Couch" 1971 (85 Harvard Law Review 392,429); Watson, "The Quest for Professional Competence: Psychological Aspects of Legal Education" (1968) 37 U.Cin.L.Rev.93 and n.10 above.

26 Barnhizer D. "The Clinical Method of Legal Instruction: Its Theory and Implementation" 197930 Journal of Legal Education 67, 7475. See also Chief Justice Warren Burger "The Role of the Law School in the Teaching of Legal Ethics and Professional Responsibility" 198029 Cleveland State Law Review 377 and Condlin R. "Socrates New Clothes: Substituting Persuasion for Learning in Clinical Legal Instruction" 40 Maryland Law Review 1981223. 
Lawyers, like doctors, have been taught how to manipulate the ideas and rules of their disciplines without any fundamental operational framework: ethical, social or political. ${ }^{28}$ The experience of practice without the tutoring or monitoring of the clinic does not seem to encourage the learning of legal skills. ${ }^{29}$ Clinical education seems to provide a half-way house in which operational standards and skills can be meaningfully learned, although one writer has cast some doubt on how well clinical legal education has dealt with questions of morality. ${ }^{30}$ One can only echo Condlin's view that thorough research into the nature of the education and training process and the skills and values that are taught is needed. ${ }^{31}$

Although clinical education moves the emphasis from learning substantive knowledge to more process oriented learning, ${ }^{32}$ this should not be seen as the academic ceding to the practical. Phil Jones suggests that, "the argument is rather that professional knowledge cannot be conceptualised within the theory-practice dichotomy." ${ }^{33}$ Clinical education, he suggests, begins to address issues surrounding the learning of both practical and intellectual skills necessary for a good lawyer: "Professional knowledge, though, involves constructing problems from situations which are puzzling, troubling and uncertain. It requires a combination of knowledge, skills and attitudes that cannot be separated out into separate spheres and learned in separate institutional processes." ${ }^{34}$ A shift towards an integrated learning environment such as the clinic encourages students to learn interactively as a means of developing both substantive and procedural knowledge as well as learning how to learn for themselves.

\footnotetext{
28 Research into criminal lawyers suggests that the theoretical understanding that defence lawyers have of criminal justice is rapidly challenged by the practical realities of defence work (at least realities as the courts and prosecution lawyers paint them). Lack of any 'operative rationale' for their theoretical conceptions encourages a quick and unquestioning adaptation to the behaviour of those lawyers they come into contact with. Blumberg, "The Practice of Law as a Confidence Game", op.cit. Baldwin and McConville "Plea Bargaining".

See, e.g. Sherr (1986), Economides (1991). Rosenthal evaluated the negotiation skills of U.S. lawyers and suggested that $77 \%$ of a sample of personal injury claimants did worse than they should have done: Douglas E. Rosenthal; "Lawyer and Client: Who's in Charge?" (New York, Russel Sage Foundation 1974).

Condlin idiosyncratically suggests that clinical education is founded on an 'immoral' learning process because early teachers had no articulate theory of instruction. He suggests that teacher-student communication should be an object of study, similar to the approach of Watson,A. "The Lawyer in the Interviewing and Counselling Process" 1976. Condlin, op.cit. See e.g. Boone, Jeeves and Macfarlane; 'Clinical Anatomy: Towards a Working Definition of Clinical Legal Education', op.cit.

33 Jones observes that the profession complains that, "law graduates lack the ability to write in clear English or construct a written argument and it argues that law graduates have very real gaps in their knowledge of the substantive core." Phil Jones, 'A Skills-Based Approach to Professional Legal Education', 1989 Law Teacher. For further academic criticisms of lawyer competence see e.g. Peden "The Role of Practical Training in Legal Education: American and Australian Experience (1972) 24 Journal of Legal Education 503, 517. 


\section{SUMMARY}

The systems for learning law and legal skills are therefore presented in the literature as a stark choice between two extremes. On the one side is traditional "declarative" knowledge taught within undergraduate study and at the stage of Law Society Finals. On the other extreme is the "procedural" knowledge of 'how it is really done', not taught but learned (if at all) through experience or passive modelling. Clinical Legal Education sits between the two in an attempt to integrate them within an open, dynamic context.

Some questions therefore arise from this literature, against the background of lawyers' assertions that the only way to learn such knowledge is from the experience of doing the work itself. Is experience alone necessarily a good teacher? Can experience be sufficient, without training, in picking up legal skills? Are more experienced practitioners necessarily more competent at legal skills than their less experienced juniors? These were the issues addressed by this research.

\section{METHOD}

This study took place in the "real world" of lawyers' offices in which 143 first interviews with new clients were video-taped and then subjected to analysis. Lawyers and clients were willing participants and refusal rates among clients were low. ${ }^{35}$ Lawyers from a range of firms spread geographically (see below) were contacted initially to secure their involvement in the study. There were a number of refusals at this stage and it proved impossible to provide a statistically random sample on this basis. In the event, the overall difference between the lawyers and firms studied and the national norms were not great; and these are set out below. But the sample is intentionally skewed towards the smaller, high-street firms operating largely within the areas of personal law and operating with a significant proportion of legal aid funding. This was necessary in order to find a range of lawyers (in terms of experience) regularly carrying out first client interviews. Lawyers were selected from a spectrum of experience starting with trainee solicitors and ranging to lawyers in the 40 - 49 age group.

The video tapes of client interviews were assessed, as in the previous laboratory based studies, ${ }^{36}$ in three ways. Expert legal assessors considered how well the lawyers had performed on some thirteen tasks to be carried out in a first client interview, how well the lawyers performed on some nineteen techniques or sub-skills which should be used in lawyer-client interviewing and also on the quality of some twelve categories of information emerging during the interview.

In addition the lawyers who had carried out interviews were asked immediately afterwards to consider how well they felt the interviews had gone including their communication with the client, the advice they had given, how satisfied they thought the client had been with the interview and their perceptions of the degree of shared control between lawyer and client in the interview. ${ }^{37}$ The clients were similarly questioned on standard forms immediately after the

\footnotetext{
35 There were six refusals by clients on grounds of sensitivity of the issues involved and confidentiality; and two occasions where lawyers felt that the interview should not continue to be taped because of sensitivity of the client or issues.

36 See note 1 above

37 See Rosenthal, D. "Lawyer and Client: Who's in Charge?" Russel Sage, New York (1977).
} 
interviews about their perceptions of how the interview had gone, thus enabling a direct comparison of both parties' reactions.

A number of other measures were also taken. Where a second client, or someone else, accompanied a client into the interview, they were also asked to assess how the interview had gone on a similar form. Delay in starting the interview was also noted, as were the conditions of the reception area and the waiting room. The time of the interviews was noted and the length of the interview. Full details of the lawyers' experience in interviewing prior to the studied interview were noted as was any training in interviewing and how they were "broken in" to interviewing clients by themselves. Information about the firms was also gathered, their geographical location, the mix of work and a client's eye view of perception of atmosphere within the firm.

\section{DESCRIPTIVE DATA}

\section{A. Client Characteristics}

\section{Social Class Gender and Race}

In the 143 interview tapes analysed, $62.8 \%$ of the clients were judged by the lawyers to be "middle class" and 26.4\% "working class". The researcher assessed $65.3 \%$ as working class and $30.6 \%$ as middle class.

$53.4 \%$ of the clients were male and $46.6 \%$ were female. Of those accompanying the clients into the interview 19 were male and 24 female. Most clients were white $(76.9 \%) . \quad 15.5 \%$ were Black/Caribbean in origin and a further $4.8 \%$ were Asian.

The ages of the clients ranged as follows:

$\underline{\text { Table I Age of Clients }}$

\section{Age of Clients $\quad \%$}

$\begin{array}{ll}15-19 & 11.5 \\ 20-24 & 12.2 \\ 25-29 & 12.9 \\ 30-39 & 25 \\ 40-49 & 20.9 \\ \text { over } 50 & 14.4\end{array}$




\section{B. Lawyer Characteristics}

\section{Gender and Race}

$68 \%$ of the lawyers were male and $32 \%$ were female. This compares with a gender balance of $73 \%$ male: $27 \%$ female in the Law Society Annual Statistical Report $1993^{38}$ for the profession as a whole. The majority of the lawyers were white (98.6\%) and the remainder Asian (1.4\%). In 1993 2.3\% of solicitors with Practising Certificates were from ethnic minorities, as certified by the Commission for Racial Equality. ${ }^{39}$

$\underline{\text { Table II Age of Lawyers }}$

\section{Ages of Lawyers}

$0-24$

$25-29$

$30-39$

40 - 49

\section{$\%$}

20

16.6

61.4

2.1

Law Society Estimate $1993^{40}$

$-30$

30-39

40-49

$50+$

\section{$\%$ \\ 17 \\ 38 \\ 29 \\ 16}

$23.8 \%$ of the "lawyers" in our sample were trainee solicitors (articled clerks) and $75.5 \%$ were qualified. $^{41}$ Our lawyers were in general a little younger than the average solicitors population, but some of this difference is taken up by including trainees in the sample.

\footnotetext{
$38 \quad$ p.79.

$39 \quad$ Law Society Annual Statistical Report 1993, p.5.

40 This estimate for all solicitors with Practising Certificates does not include trainee solicitors. Law Society Statistical Report 1993 , p.9.

41 Differences according to the various levels of experience will be analysed.
} 


\section{Length of Practice}

The length of time the lawyers had been practising was recorded.

Table III Length of Practice

$\begin{array}{lc}\text { Length of time } & \mathbf{\%} \\ & \\ \text { First six months } & 1.2 \\ \text { Second six months } & 4.7 \\ \text { Second year } & 1.2 \\ \text { First five years } & 21.0 \\ \text { Six to ten years } & 48.8 \\ \text { Eleven to twenty years } & 23.3^{42}\end{array}$

Solicitors in Private Practice $1993^{43}$

Length of time

$0-9$ years

$10-19$ years 32.2

$20+$ years

\section{Interview Experience}

Note was taken of the difference in time since their first solo interview and the date of the research for subjects in the first five years of qualified practice as solicitors. The mean time was 75.98 months, or just over six years, suggesting that for those lawyers the average time for a first solo interview was about a year and a quarter into the training contract (articles).

For this sub group a note was taken of any prior training in interviewing. The majority had no training, no subject recording training at University, Polytechnic or Law Society courses. A small group had specific instructions from their seniors and one subject had training as part of a previous employment.

Interview experience prior to articles was also often limited. The majority of subjects under 5 years qualification reported no such experience, with a small group reporting exposure at advice centres and another group gaining experience in other jobs.

\section{Introduction to Interviewing}

None of the lawyers, as a whole group, had been allowed to interview prior to the third month of articles and a few only conducted their first solo interview at six months. As the method of

\footnotetext{
42 As lawyers carried out more than one interview for the study, demographic data was only gathered once for each lawyer.

$43 \quad$ Law Society Annual Statistical Report 1993, p.11.
} 
introduction to interviewing may be a crucial factor in competence and confidence it was of interest to note that a small group were simply plunged into their first interview whilst the remainder sat in on interviews; a form of passive modelling. No subject reported that a more experienced lawyer had sat in on their first interview to give critique or feedback (active modelling).

\section{Characteristics of the Firms}

\section{Work Orientation}

Subjects described their firms. $68 \%$ were seen as mainly business oriented, $29.5 \%$ as mainly personal law and $2.3 \%$ reported a mixture. Subjects estimated the percentages of time dedicated to various subject areas of law by their firm.

\section{Table IV Type of Work}

\section{Subject}

Commercial/business

Criminal

Property

Matrimonial

Personal

\section{Mean \%}

22.1

28.1

The subjects recorded a mean of $62.2 \%$ legal aid work carried out in their firms. The Chambers and Harwood Study showed $18 \%$ of cases in the law firms they investigated being funded by Legal Aid and those cases produced only $10 \%$ of gross fees. ${ }^{44}$ The sample represented here concentrates on solicitors mainly working in personal law issues and operating in the "High Street" rather than "commercial practice". This is also the group which would have a higher throughput of client interviews, thus enabling the objectives of the research.

\section{Geography}

$55.7 \%$ of the firms were based in the inner city, $20.5 \%$ in the city suburbs, and $23.9 \%$ were from smaller towns.

\section{Size}

\section{$\underline{\text { Solicitors }}$}

$43.2 \%$ of the firms had between $2-5$ solicitors, $31.8 \%$ had between $6-10$ solicitors and $25 \%$ had over 11 solicitors. The Law Society 1993 statistics show an average of 5.8 solicitors per firm. ${ }^{45}$

\footnotetext{
$44 \quad$ Law Society Annual Statistical Report 1990 p.61. The most recent figure in the 1993 Annual Report shows gross fees from legal aid at $11.8 \%$ (p.51). 
$13.6 \%$ of the firms had no trainee solicitors, $23.9 \%$ had 1 trainee, $58 \%$ had $2-5$ trainees and $4.5 \%$ had 6-10 trainee solicitors.

\section{$\underline{\text { Partners }}$}

$11.4 \%$ of firms had one partner, $43.2 \%$ had between 2 and 5 partners, $34.1 \%$ between 6 and 10 partners and 11.4\% over 11 partners. The Law Society Annual Statistical Report for 1993 showed $39 \%$ sole practice firms and $43 \%$ of firms with 2-4 partners, $14 \%$ with 5-10 partners and $5 \%$ with more than 11 partners. ${ }^{46}$ The firms in this study were therefore skewed towards the middle and upper levels of the national range. It was necessary to identify such firms in order to ensure a regular throughput of new clients.

\section{Formality}

The formality of the firms was assessed by the researcher based on the firm's external and internal appearance, relationship between legal and support staff and approach to visitors. Most of the firms tended towards the informal. "Extra informal" firms might have chatty waiting rooms, children running around, etc.

$\underline{\text { Table V Formality of the Firms }}$

\begin{tabular}{lc}
\hline & \\
Extra informal & \\
Informal & 14 \\
Middle & 43 \\
Formal & 37.6 \\
Extra formal & 1.1 \\
& 4.3
\end{tabular}

\section{Reception and Waiting Room - The Atmosphere of the Firm}

Waiting rooms were also rated by the researcher on a $1-5$ scale from $1=$ pleasant to $5=$ unpleasant. The mean score was 2.8 with no firm scoring at 5 and $6.8 \%$ scoring at 4 .

$1.9 \%$ of firms had privacy from the street in the waiting room, $9.5 \%$ were very public waiting rooms and the remaining $88.6 \%$ were neither completely open to public view nor private.

Greetings by the receptionist were coded by the researcher. $54.5 \%$ were friendly, $25 \%$ middle and $20.5 \%$ formal.

Some basic provisions were also looked for along the lines of what might be expected in High Street practice. The following table shows in what proportion of firms these were present.

Table VI Waiting Room Provisions

$46 \quad$ Ibid. p.23. 
Provision

Telephone for waiting clients

Directions to the toilet

Toys for children

Political/community literature

Legal or Welfare literature

Information on housing/mortgages 40.8

Plants

Pictures on the walls

Ashtrays

Newspapers
1.9

10.7

13.6

24.3

\section{4}

59.2

74.8

86.4

\section{Interview Characteristics}

\section{INTERVIEW LENGTH}

Interviews lasted a mean of 38.6 minutes (standard deviation 23.1) ranging from the shortest, 4 minutes, to the longest interview at 140 minutes.

\section{Timing}

Interviews took place on all days of the month and all months of the year under study, except December. $18 \%$ of the interviews took place in the morning (before 1.00 p.m.) and $81.6 \%$ in the afternoon. The afternoon appeared to be a more convenient time for both parties, and morning court appearances meant that many of the lawyers were not available then for interviewing clients.

\section{Delay}

Waiting time has been noted as a major factor in ultimate dissatisfaction in medical consultations $^{47}$ and lawyers' clients have also complained of being kept waiting without explanation. In these legal interviews one client was seen over half an hour early, and $6.2 \%$ of clients were seen between 11 and 30 minutes early. The majority of clients $(50.3 \%)$ were seen either on time or within ten minutes before or after their appointment time. Some $30.3 \%$ of clients were seen between 11 and 30 minutes late and 7\% were kept waiting in excess of half an hour.

When delays occurred, the reasons for delay were noted in Table VII below.

47 See Ley, P. "Psychological Studies of Doctor-Patient Communication" in S.J. Rachman (ed) 1977 'Contributions to Medical Psychology' Vol. 1 Pergamon Oxford pps 9-37. 
Table VII Reasons for Delay

\section{Reason for Delay}

Late return of lawyer

Lawyer involved in work

Lawyer/client appointment time differs

Delay by client ${ }^{48}$

\section{Number}

2

33

2

\section{Collection}

The way the clients were collected from the reception area may also be of importance in the way an interview proceeds. A detailed analysis of how the different firms carried out this procedure is presented below:

\section{$\underline{\text { Table VIII Client Collection }}$}

\section{Client Collection Method $\quad \%$}

1. Lawyer comes out and escorts client to room 43.3

2. Receptionist/Secretary tells client where to go 23.4

3. Other.

\section{$\underline{\text { Interruptions }}$}

Interruptions occurred and were noted by the assessor in 43 of the interviews as shown in Table IX below. An interruption can destroy the flow or confidentiality of the interview and may belie the lawyer's show of interest in the client. It is therefore interesting to see how often these occur in practice.

In almost a quarter of cases covered by "Other" the researcher was asked to carry out client collection either by receptionist or lawyer following the researchers obtaining the client's agreement to being filmed and being involved in the research. It is not known how client collection would have taken place in the absence of the researcher, but it seems likely that it would have conformed to 1 and 2 above.

\section{$\underline{\text { Table IX Interruptions }}$}

Dictaphone usage

Received substantial t/call

Made outgoing telephone call

Received but denied call

Left room
$32.6 \%$

$23.3 \%$

$9.3 \%$

$2.3 \%$

$2.3 \%$

48 On four other occasions a short delay occurred whilst the researcher was still involved in checking whether the client was happy to be involved in the research. 
Someone entered

$2.3 \%$

Other interruptions

$27.9 \%$ 
Although some outgoing telephone calls will be intended to be helpful immediately for the client, often this was a disturbance to the interview and exposed the difference in the lawyer's approach to other lawyers (pleasant, respectful) and approach to the client (patronising, demeaning). The client's inability to listen in to the other side of the conversation also distanced the client from the lawyer. It is therefore questionable whether it is appropriate on most occasions to use the telephone during an interview, unless urgent to do so, or because a call can bring some immediate relief to client anxiety. Both telephone and dictaphone are lawyer-centred ${ }^{49}$ tools of the trade and must constitute some interruption to the interview process, although clearly both might be necessary at times. There seems to be little excuse for receiving a substantial telephone call during an interview relating to another matter.

\section{E. Case Characteristics}

A range of some 14 different categories of legal matter were covered by the interviews under research. The most common type was Family matters (accounting for 31\%), followed by Criminal (accounting for 28\%). A breakdown of the categories is shown in Table $\mathrm{X}$ below:

$\underline{\text { Table X Work Categories of Cases }}$

Category

Family

Crime (incl. juvenile \& Motoring)

Personal Injury, Medical Neg.

and Criminal Injury

Employment

Wills and probate

Housing, Landlord and Tenant

Consumer

Discrimination

Neighbour disputes

Immigration

Conveyancing

Complaints against police etc

Welfare Benefits

Other

\section{Frequency}

43

39

14

7

6 $\underline{\text { Percentage }}$

$31.0 \%$

$28.1 \%$

$\begin{array}{cc} & 10.0 \% \\ & 5.0 \% \\ 4.3 \% & \\ & 3.6 \% \\ & 2.9 \% \\ 2.9 \% \\ 2.9 \% \\ 2.2 \% \\ 1.4 \% \\ 1.4 \% \\ 1.4 \% \\ 2.9 \%\end{array}$

$100(99.7)$

$2.9 \%$

$2.9 \%$

$2.9 \%$

$2.2 \%$

$1.4 \%$

$1.4 \%$

$1.4 \%$

$2.9 \%$

$100(99.7)$

This table can be compared with the figures found by Chambers and Harwood under slightly different headings assessed according to case numbers and by income. ${ }^{50}$

\footnotetext{
49 See Sherr, A.H. Client Interviewing for Lawyers. 1986 (Sweet and Maxwell) London.

50 See Chambers, G. and Harwood Richardson, S. "Solicitors in England and Wales. Practice Organisation and the Private Practice Firm. RPPU 1991.
} 
Table XI Chambers and Harwood's Percentages of Case Categories by Numbers and Income

Category

Family and Child Care

Crime

Personal Injury

Employment

Probate/Wills

Housing

Consumer problems

Resid. Conveyancing

Welfare Benefits

Business affairs

Commercial Property

Bankruptcy

Personal finance

Case numbers

Income

$1994^{51}$

\begin{tabular}{|c|c|c|c|}
\hline $10.0 \%$ & & $6.6 \%$ & $8.0 \%$ \\
\hline $7.9 \%$ & $4.0 \%$ & $3.4 \%$ & \\
\hline $7.9 \%$ & $5.3 \%$ & $6.0 \%$ & \\
\hline $1.3 \%$ & $1.3 \%$ & & \\
\hline $8.3 \%$ & $7.1 \%$ & $8.0 \%$ & \\
\hline $2.6 \%$ & $2.0 \%$ & & \\
\hline $1.1 \%$ & $.5 \%$ & & \\
\hline $31.0 \%$ & & $21.2 \%$ & $11.0 \%$ \\
\hline $0.4 \%$ & $.1 \%$ & & \\
\hline $12.4 \%$ & & $28.6 \%$ & $30.0 \%$ \\
\hline $9.8 \%$ & & $18.2 \%$ & $15.0 \%$ \\
\hline $2.6 \%$ & $1.3 \%$ & & \\
\hline $1.0 \%$ & $1.3 \%$ & & \\
\hline
\end{tabular}

It is clear that the sample of practitioners studied here deals much more with Criminal and Family law than the 'average practitioner' portrayed by Chambers and Harwood in 1991 and the latest results from an internal Law Society paper. This is also borne out by the comparative figures for work funded by Legal Aid mentioned above (62.2\% compared with $18 \%$ for Chambers and Harwood). The sample of solicitors studied here would as a result also be more involved from traineeship onwards in client interviewing and regularly conduct first interviews with new clients.

\section{EVALUATION OF THE INTERVIEWS}

A series of evaluations were carried out. The interviews were evaluated immediately afterwards by each lawyer and client separately. Subsequently, a more detailed evaluation was carried out by an expert legal assessor trained in evaluation.

\section{THE LAWYER'S AND CLIENT'S EVALUATION OF THE INTERVIEW}

After the interviews both the lawyers and the clients completed an evaluation form. A series of satisfaction items were covered. These were rated on a 7 point analogue scale - 1 representing low satisfaction and 7 maximum satisfaction. To ensure against response set or bias every second questionnaire altered the labelling of these poles. For the purpose of the analysis these were transformed. Table XII compares the mean scores for the lawyers and the clients.

Table XII Comparison of Lawyer's and Clients' Perceptions of the Interviews

\section{Mean Scores}

These figures are taken from an internal Law Society RPPU document showing approximate proportions of gross fees for 1993-1994. 
Lawyer

How satisfied were you with the way you spoke to the client?

How satisfied do you think the client was?

How satisfied were you with the advice and plan of action you stated?

How satisfied do you think the client was with the advice/ plan of action?

How confident was the client in you?

\section{3}

Client

\section{2}

How satisfied were you

with the way you were
5.2
spoken to?
6.7
$14.9 \quad .001$

\section{Paired Sig \\ $\underline{\mathbf{T}} \quad \underline{\mathrm{P}}$}

\section{5}

How satisfied were you with the advice/plan
5.3 of action
6.6 $\quad 10.9$
.0001

In general the lawyers were very satisfied with their interviews and thought that their clients had been even more satisfied. The Lawyers were asked how satisfied they were with the way they had spoken to the client. The mean rating was 5.2 on the $1-7$ scale (SD2.3, mode 6.0 ). $9.9 \%$ of the sample rated their communication under the midpoint with a further $12.2 \%$ self rating at maximum. The lawyers were then asked to rate how satisfied they thought the client had been with the lawyer's communication. The mean was similarly high (5.2 with a SD of 1.2$)$. Only $8 \%$ thought this was under the midpoint and a further $43 \%$ thought they had performed at, or just under, the maximum.

Overall client ratings were significantly higher than those of their lawyers on a matched pairs $t$ test. Their satisfaction with the way the lawyer spoke to them scored a mean of 6.7 (SD 0.8) with $73 \%$ maximally satisfied and only $0.7 \%$ scoring under the midpoint.

Lawyer interviewers were also generally satisfied with the advice and plan of action they had given their clients (mean 5.5, SD 1.4). Again 9.4\% scored under the midpoint whilst 54.7\% scored at or just under maximum. They felt the clients were also highly satisfied with this advice (mean 5.3, SD 1.3). Only two subjects thought clients were dissatisfied (scoring at 1) whilst $47 \%$ thought their clients to be maximally satisfied (points 6 or 7). The lawyers also felt they had gained considerable client confidence (mean 5.3, SD 1.2) with only one subject $(0.7 \%)$ scoring at 1 and just under half (48.6\%) scoring at 6 or 7 . 
Clients rated the advice or plan of action suggested by the lawyer (6.6 mean, SD 0.9) again significantly higher than the lawyers with $72 \%$ maximally satisfied and $0.7 \%$ again scoring below the midpoint. Client confidence in their lawyers was also significantly higher than the lawyers thought with a mean of 6.6 (SD 0.9). $2.2 \%$ scored confidence in their lawyers below the midpoint and $73 \%$ were at the maximum level.

When asked who they felt was 'in charge' of the interview, $2 \%$ of both lawyers and clients said that the client was in charge, 33\% of lawyers thought control had been shared equally between themselves and the client and 59.5\% thought they had been in charge. The perceptions of the client are contrasted below in Table XIII

Table XIII "Who's in Charge?"

'Who's In Charge'

Client

Lawyer/Client equally

Lawyer
Lawyer Response Client Response

$\begin{array}{lc}2 \% & 2 \% \\ 33 \% & 51.4 \% \\ 59.5 \% & 38.5 \%\end{array}$

Clients agreed that they were not in control. However, more thought they had joint charge than their lawyers endorsed.

Over half the lawyers gave further comments on the interview (52.7\%). Of these, $43.5 \%$ were negative comments, $25.2 \%$ were positive, $1.6 \%$ mixed and $27.4 \%$ neutral.

$62.2 \%$ of clients gave further comments on their questionnaires. Of these, $7 \%$ made negative comments, $79.1 \%$ made positive comments, $4.7 \%$ made mixed comments and $7 \%$ made neutral comments.

36 of the interviews had a second "client" present and these were also asked to complete questionnaires. General satisfaction was high (all subjects scored at 6 or 7 of the schedule) and satisfaction with advice was also high, with 30 subjects scoring at 7 , and the remainder at $5 \& 6$. Confidence in the lawyer was also high (all subjects rating at 6 or 7). Overall the presence of a second client sheds a favourable light on the interview. It may be that more proficient interviewers are more at ease and therefore happy to invite partners in. However, the well-being and confidence of the client may also be greatly enhanced by the presence of a social support or partner.

The considerable literature ${ }^{52}$ on client dissatisfaction with their solicitors' communications skills seems at variance with the generally high level of satisfaction reflected in the questionnaire

\footnotetext{
52 See e.g. The Royal Commission on Legal Services Final Report, Cmnd. 7648, 7648-1- Vol. One 3.36-7, 22.29-31, 22-62. Tables 22.3, 22.4; Vol. Two 8.228-30, 2.238, 8.252-72, Tables 8.34, 8.35, 8.36, 8.37; B. Curran "The Legal Needs of the Public" (1978) ABA Jo. 843-52; Marre "A Time for Change" 1988 pps 52-53; "The Place of Communication Skills in Lawyer Education" National Consumer Council, 1990.
} 
responses of this client sample. It is apparent that their own perceptions of how well their initial interviews were conducted are even higher than those of their lawyers.

In general client satisfaction with professional work is high and dissatisfaction with doctors' communication has been distinguished from happiness with the work itself ${ }^{53}$. A distinction between the work of lawyers and doctors may be instructive here. The General Practice medical doctor often carries out the entire transaction of diagnosis, advice and treatment within the singular context of one consultation. The initial interview with a lawyer is only the first step in a more protracted transaction. Lawyers' image management may therefore be easier for the lawyer ${ }^{54}$ who can promise much in the first interview but whose work and communication later may not necessarily live up to these early expectations.

Important distinctions may therefore be drawn between the first blush of a client's cathartic unburdening of their problems to a listening professional and subsequent consideration of the lawyer's interviewing performance compared with the reality of work carried out and promises fulfilled.

\section{EXPERT EVALUATION OF INTERVIEW PERFORMANCE}

All interviews were videoed and the video tapes were subsequently subjected to further analysis in accordance with the methodology developed in previous work ${ }^{55}$. Assessment was conducted by an experienced legal interviewing trainer, who was also professionally and academically qualified in the practice and teaching of law. The assessor was trained in the methodology of assessment and worked blind to the hypotheses under examination. The data for the whole sample is reported below. Subsequent breakdown is also reported.

A 13 point plan based on the fundamental tasks of an interview were applied to the interviews as in the previous research ${ }^{56}$. Table XIV below sets out the tasks together with the performance. Tasks were rated as before on a 7 point analogue scale $(1=$ very bad, $2=$ bad, $3=$ fairly bad, $4=$ average, $5=$ fairly good, $6=$ good and $7=$ very good).

\footnotetext{
$53 \quad$ See Ley, P. op. cit. n. 41.

$54 \quad$ See e.g. Blumberg, 'The Practice of Law as a Confidence Game' (1967) 1 Law and Soc. Rev. 15.

55 See Fn.1 above

$56 \quad$ See Fn.1 above.
} 
Table XIV : Task Competence: Mean scores and Percentage falling below "average" rating.

\section{Variable}

Greetings seating and introduction

Opening question or helpful silence

Obtaining basic personal/party info

Factual Questioning

Sum up facts/recount/check

Note taking

Statements of advice/plan of action

Restate advice and obtain client agreement

Recount client follow up

Recount lawyer follow up

Set next meeting/contact

Ask for any other business

Termination and goodbye
Mean Rating $\%<A v$

4.2

37.3

3.9

4.1

45.1

4.8

35.3

3.8

17.6

3.9

57.8

37.3

4.8

13.7

4.2

28.7

27.7

4.5

4.3

3.3

4.2
32.7

29.7

Overall, performance was scored around the "average" point for the tasks assessed. However, a high percentage of the interviews scored below average (very bad, bad or fairly bad) on all items. There were particular problems with some key elements of an interview. The opening sections of the interview were poorly carried out, leaving the entire listening stage with more than a third of performances below average. Higher scores were obtained for questioning and advice but summarising facts and checking with the client for their accuracy was especially poor with $57.8 \%$ below average. The highest failure rate of $76.5 \%$ below average concerned asking the client if there was anything further they wanted to mention and between a fifth and a third of the subjects scored poorly on all other variables. Questioning and advising are highly important tasks but their efficacy can be seriously impaired by poor listening at the beginning of the interview. It also seems clear that the preferred style of questioning rather than listening to the client is not so efficient in use of time and is likely to be less satisfying to clients.

A further series of measures revealed that although $83.7 \%$ of the lawyers stood up to meet their clients when they entered the room and $84.5 \%$ seated them adequately, 38.3\% did not greet them and $83.2 \%$ did not introduce themselves properly. Beyond the social niceties, $76.6 \%$ did not specifically gain the client's agreement to the lawyer's understanding of the facts as expressed and $51 \%$ did not get the client's agreement to the advice or plan of action offered. $85.4 \%$ of the lawyers did not enquire whether there was anything else the client wished to discuss before ending the interview. In medical interviews a syndrome (appropriately identified as the "hand on the doorknob syndrome") reveals that many major problems (sometimes the main reason for attendance) are revealed on departure. ${ }^{57}$ Intuitively, this may well be a factor in legal interviews. However, getting up from their seats at the end of the interview, as in the beginning, was not a problem for the $88.3 \%$ who did so but $22.6 \%$ did not actually manage to say goodbye.

Interview Techniques

Byrne and Long "Doctors talking to Patients" DHSS, 1972. 
A further analysis, rated in similar fashion, was undertaken into the proper use of 19 techniques employed over the range of the above tasks by the lawyers under observation in accordance with the methodology developed previously. ${ }^{58}$ The data is presented in Table XV below.

$\underline{\text { Table XV Technique Competence: Mean Scores and Percentage falling below "average" rating }}$

Techniques

Coverage of personal information

Over-acceptance of client's jargon

Overuse of legalese

Precision in obtaining information

Picking up clients verbal cues

Over-repetition of same topics

Clarification of gaps or confusions

Useful control of client and irrel info

Facilitation of client talk

Overuse of leading and closed questions

Use of complex questions

Ease with client

Empathy with client

Time control throughout interview

Opening and close ease \& control

Reassuring of client

Quality of advice/plan action

Efficiency in obtaining information

Picking up clients non verbal cues
Mean Score

4.3

4.6

4.3

3.9

4.5

4.8

4.0

3.8

4.7

4.4

3.5

4.4

23.9

4.3

4.5

4.2

3.8
$\%<$ Av

36.3

5.0

31.4

29.7

42.2

9.8

14.9

12.7

49.0

40.2

5.9

25.5

51.0

30.9

32.0

32.0

Once again overall performance inclined towards the "average" but there was greater variability in scores on individual items. Few lawyers scored below "average" on handling clients' jargon, over-repetition, complex questions or control of client. The highest failure rates were on facilitating of clients to talk, picking up verbal cues and showing empathy with the client. These demonstrate how the deficiencies at the listening stage of the interview noted above are expressed through poor technique in encouraging client involvement. Over-use of leading and closed questions similarly portrays the tendency toward lawyer-centred activity, ${ }^{59}$ through questioning rather than listening. Covering personal information, overusing legalese, precision, reassurance, efficiency and picking up non-verbal cues all show failure rates around the $30 \%$ level; and the quality of the advice or plan of action given shows a similar rate of failure.

An overall rater assessment on absolute categories noted that $64.4 \%$ used legalese, $88.5 \%$ were able to avoid complex questions, $92.2 \%$ did not inform the client about the time available for the

\footnotetext{
$58 \quad$ See Fn.1.

$59 \quad$ See Binder, Price and Bergman "The Lawyer as Counsellor" 1991, pps 20-21.
} 
interview. Whereas $92.9 \%$ of the lawyers gave advice during the interview and $70.1 \%$ gave a plan of action either as an alternative or as an extra.

\section{$\underline{\text { Information }}$}

As in previous studies, the quality of the information obtained and given by the lawyers was also rated in similar fashion over 12 separate headings in order to assess the effects of competence levels in tasks and techniques. Table XVI below sets out the ratings.

Table XVI Information Quality: Mean Scores and Percentage below "Average" rating

Information

Client personal information

Other parties

Witnesses

Problem subject categorisation

Events

What the client wants

Previous advice or assistance

Legal proceedings

Next contact for Client/Lawyer

Work to be done by Lawyer

Work to be done by Client

Advice given
Mean $\quad \%<A v$

$4.4 \quad 31.4$

$3.8 \quad 38.2$

$3.7 \quad 36.3$

$5.1 \quad 2.9$

$4.4 \quad 31.4$

$4.9 \quad 14.7$

$4.1 \quad 24.5$

4.3

$4.2 \quad 35.4$

$4.5 \quad 25.7$

The lawyers were very good at pigeon-holing the subject matter of the client's problem into a legal subject category and there were only $14.7 \%$ failures in extracting and understanding what the client wanted out of their difficulty. There were $22-24 \%$ failures on the existence and details of legal proceedings and any previous legal advice or assistance but comparatively higher levels of failure on the events occurring which gave rise to the problem, the other parties involved and any witnesses to material events. These would be important information concerns in the continuation and representation of the client's case, although some of this information could be picked up in later interviews or in correspondence.

The interview expert assessor made further comments which were not contained within the analysis schedules. Such comments were made on 59 interviews and of these comments, $54.2 \%$ were negative comments about the interviews, $16.9 \%$ positive and in $28.8 \%$ they were mixed. 


\section{Experience and Competence}

In this study it was then possible to compare interview performance with the level of the lawyers' experience. Correlations were run between length of qualification and performance of the lawyers in satisfying clients, abilities in tasks and techniques and obtaining information. If interview competence improved with practice, the passage of time or experience, there would be a significant correlation between level of performance and length of qualification. Pearson correlations showed no significant relationship, (Techniques $r=0.06 \mathrm{p}=0.3 \mathrm{~ns}$, Tasks $\mathrm{r}=0.12$ $\mathrm{p}=0.2 \mathrm{~ns}$ ). This result is counter intuitive. Lawyers certainly feel that they improve with experience and some of the literature surveyed above certainly suggests that major improvement can result from experience.

A closer examination was therefore made of what might be signified by the notion of experience. The concept of "experience" could involve simply the passage of time, the amount of practice a lawyer has had in interviewing, or more specifically practice in the presence of, or following, training? It is also possible that competence could grow in a stepwise fashion with a concentration in growth around practice milestones such as the passage from trainee solicitor (articled clerk) to qualified solicitor.

To set about examining some of these issues, a comparison was first run between the interview results of trainee solicitors (TS) and qualified solicitors (QS).

\section{Comparison of Trainee Solicitors and Qualified Solicitors}

Comparisons were run on all variables between the interviews conducted by trainee solicitors (articled clerks) and those conducted by qualified solicitors. Table XVII below sets out findings based on the lawyer and client questionnaires.

$\underline{\text { Table XVII Comparison of Trainees and Qualified Solicitors on Lawyer and Client Assessments }}$

Variable

1. Lawyer Questionnaire

How satisfied were you with the way you spoke to the client?

How satisfied do you think the client was?

How satisfied were you with the advice and plan of action you stated?
Mean Score

$\mathbf{T} / \mathbf{Q} / \mathbf{S}$
$4.1 \quad 5.4 \quad\left(3.8^{* * *}\right)$

$\begin{array}{lll} & 5.7 \quad(2.3 \mathrm{~ns})\end{array}$

How satisfied do you think the 
client was with the plan/advice?

How confident was the client

in you?

2. Client Questionnaire

How satisfied were you with the way you were spoken to?

How satisfied were you with the advice/plan of action?

How confident were you with your lawyer?
4.7

5.6

$\left(2.4^{*}\right)$

4.6

5.6
$6.8 \quad(0.3 \mathrm{~ns})$

6.7

$6.7 \quad(0.1 \quad \mathrm{~ns})$

6.8

$6.6 \quad(0.6 \mathrm{~ns})$

* $\quad \mathrm{P}<.01$

** $\mathrm{P}<.001$

$* * * \quad \mathrm{P}<.0001$

This data shows that the qualified solicitors rated their own interview performance significantly higher than the trainee solicitors rated theirs on all variables except their own satisfaction with their advice and plan stated (which was also higher, but not at a significant level). This is in sharp contrast to the clients' perceptions. The clients do not differentiate between the groups and showed similar satisfaction with trainee and qualified solicitors alike. This means that although the qualified lawyers had the perception that their interviews were significantly better than the trainee solicitors' perceptions of their own interviews, this effect may be the result of the confidence of experience rather than any improved performance; at least no improved performance discernable by the clients.

It should be noted that overall mean client appraisals were high and some ceiling effect might hide variation. Furthermore self-ratings were, on average, high. This is in contrast to the objective observer ratings (see below) which were generally lower. These findings could not however be accounted for by demographic and timing factors. The groups did not differ significantly in length of interview (although the mean length was 29 minutes for TS and 40 minutes for QS $\mathrm{t}=1.5 \mathrm{~ns}$ ). There was also no significant difference in the age of clients seen $(\mathrm{t}=0.04 \mathrm{~ns})$. 
Comparisons were then drawn on Tasks and Techniques Assessments for the two groups. The findings on Tasks are set out in Table XVIII below.

$\underline{\text { Table XVIII Comparison of Tasks Scores between Trainee and Qualified Solicitors }}$

Tasks

Greetings seating and introduction

Opening question or helpful silence

Obtaining basic personal/party info

Factual Questioning

Sum up facts/recount/check

Note taking

Statements of advice/plan of action

Restate advice and obtain client

agreement

Recount client follow up

Recount lawyer follow up

Set next meeting/contact

Ask AOB

Termination and goodbye
Mean Score

TS QS

$\begin{array}{llll} & 4.1 & 0.4 \mathrm{~ns} & \\ 1.8 & & 3.9 & 3.6 * * \\ 3.7 & & 4.1 & 1.1 \mathrm{~ns} \\ 4.3 & & 4.9 & 1.4 \mathrm{~ns} \\ 2.9 & & 4.0 & 2.2 * \\ 4.2 & & 3.9 & 0.7 \mathrm{~ns} \\ 5.1 & & 4.8 & 0.8 \mathrm{~ns}\end{array}$

4.2

$4.2 \quad 0.0 \mathrm{~ns}$

$4.3 \quad 0.5 \mathrm{~ns}$

$4.4 \quad 1.1 \mathrm{~ns}$

4.9

4.7

3.4
$4.3 \quad 0.9 \mathrm{~ns}$

$3.3 \quad 0.4 \mathrm{~ns}$

$4.2 \quad 0.5 \mathrm{~ns}$

$* \quad \mathrm{P}<0.01$

** $\mathrm{P}<0.001$

The qualified solicitors scored significantly higher on two of the 13 items, Opening Question and Summarising Facts and Checking back with the client on accuracy. The performance of the two groups did not differ significantly on the other 11 items. Mean scores were fairly consistent, being slightly above the midpoint. Significant differences were not accounted for by qualified solicitor excellence, but by poorer performance on two particular items by the trainees. This would suggest that in general the effects of experience are small but there are one or two specific areas where improvement can be directly related to it.

The techniques scores for the two groups were also compared as shown in Table XIX below.

$\underline{\text { Table XIX Comparison of Techniques Scores for Trainee and Qualified Solicitors }}$

Technique

Coverage of personal information

Over-acceptance of client's jargon

Overuse of legalese

Precision in obtaining information

Picking up clients' verbal cues

Over-repetition of same topics

Clarification of gaps or confusions
TS

\section{Mean Score}

4.0

4.4

3.2

3.9

3.2

3.7

4.3

4.1
QS

$4.4 \quad 1.0 \mathrm{~ns}$

$4.6 \quad 0.5 \mathrm{~ns}$

$4.1 \quad 2.0 *$

$4.3 \quad 1.0 \mathrm{~ns}$

$3.9 \quad 0.7 \mathrm{~ns}$

$4.5 \quad 0.7 \mathrm{~ns}$

$4.8 \quad 1.8+$ 
Useful control of client and irrel info

Facilitation of client talk

Overuse of leading and closed questions

Use of complex questions

Ease with client

Empathy with client

Time control throughout interview

Opening and close ease \& control

Reassuring of client

Quality of advice/plan action

Efficiency in obtaining information

Picking up clients non verbal cues

$* \mathrm{P}<.0$

+ Trend

$\begin{array}{lllll} & 4.3 & & 4.8 & 1.5 \mathrm{~ns} \\ & 3.3 & & 4.0 & 1.2 \mathrm{~ns} \\ 3.6 & & 3.8 & 0.7 \mathrm{~ns} & \\ 4.4 & & 4.7 & 1.2 \mathrm{~ns} & \\ & 4.3 & & 4.3 & 0.0 \mathrm{~ns} \\ & 3.7 & & 3.4 & 0.5 \mathrm{~ns} \\ 4.6 & & 4.7 & 0.3 \mathrm{~ns} & \\ 4.3 & & 4.4 & 0.2 \mathrm{~ns} & \\ & 4.3 & & 4.4 & 0.3 \mathrm{~ns} \\ & 4.4 & & 4.5 & 0.6 \mathrm{~ns} \\ & 4.4 & & 4.3 & 0.8 \mathrm{~ns} \\ 4.0 & & 3.6 & 0.6 \mathrm{~ns} & \end{array}$

Qualified solicitors were significantly better on not overusing legalese and tended to have higher ratings when clarifying gaps and confusions. On the remainder of the seventeen items there were no significant differences between the groups.

In summary therefore, it would appear that qualification of itself and experience in general do not make a significant difference to the general levels of competence in client interviewing shown by the lawyers in this sample. A small number of discrete areas do show higher levels of competence by qualified lawyers. They appear to be better at opening questions, summarising information, not using legal jargon and clarifying gaps and confusions than their trainee counterparts. Otherwise attainment, or lack, of competence do not appear to differ significantly between practitioners on behavioural assessments at these two levels.

A comparison was also made of the information obtained and given by the two groups of lawyers. Table XX below sets out the findings :

Table XX Comparison of Information Scores for Qualified and Trainee Solicitors

Variable

1. Client Personal Information

2. Other parties involved

3. Witnesses

4. Problem subject categorisation

5. Events

6. What client wants

7. Previous advice

8. Legal proceedings

9. Next contact (Client/lawyer)

10. Work to be done by lawyer

11. Work to be done by client

12. Advice given

Mean Scores

TS

4.0

4.1

4.9

3.8

3.7
QS

4.6<smiles>[13CH3]</smiles>

4.6

4.6

4.2

4.7

4.4

3.9

4.3
3.9

5.2

4.5
4.9

4.2

4.4

4.2

4.5

4.3

4.5

\section{Sig}

$1.2 \mathrm{~ns}$

$0.6 \mathrm{~ns}$

$3.8 \quad 0.4 \mathrm{~ns}$

$1.2 \mathrm{~ns}$

$1.6 \mathrm{~ns}$
$0.9 \mathrm{~ns}$

$1.2 \mathrm{~ns}$

$0.4 \mathrm{~ns}$

$0.9 \mathrm{~ns}$

$0.1 \mathrm{~ns}$

$0.4 \mathrm{~ns}$
$1.3 \mathrm{~ns}$ 
There were no significant differences found on a detailed test on any of the items measured. Although behaviourally there had been some three areas of significant difference in the qualified lawyers' performances out of the 13 tasks and 19 techniques headings measured, there were no information based categories on which the qualified lawyers performed significantly better than the trainees.

The mean scores were slightly above the midpoint on all factors for both groups. This lack of difference was therefore not due to the fact that both were performing at excellent levels which would create a ceiling effect. It seems that according to the criteria used for assessment, the passage of time and experience were not sufficient by themselves to enhance interviewing abilities. The quality of performance of experienced lawyers was not differentiated by the assessor on any information category measured. The small areas of observed difference in behaviour did not seem to effect any significant difference in the quality of information emerging.

It was therefore decided to test whether any more subtle differences occurred further up the scale of experience. A comparison was run between the interview performances of qualified solicitors in the 2-5 year range with solicitors who had been qualified between 11 and 20 years.

The analysis first considered the Lawyer and Client questionnaires.

Table XXI Comparison of Junior and Senior Qualified Solicitors on Lawyer and Client Questionnaire Answers

Variable

Mean Scores $\quad \mathbf{t}$

2-5

11-20

sig

1. Lawyer satisfaction with way

spoke

4.9

5.7

$1.8(.08)$ trend

2. How satis. lawyer thought client

with 1

4.9

5.8

$2.1(.04) *$

3. Lawyer satis. with advice

etc

6.2

$2.1(.04) *$

4. How satis. lawyer thought client with 3

$1.01 \mathrm{~ns}$

5. How confident lawyer thought

client

$2.6(.01) *$

6. Client's satis. with way lawyer spoke

$0.2 \mathrm{~ns}$

7. Client's satis. with advice etc 
8. Client's confidence in
lawyer
6.6
6.5
$0.3 \mathrm{~ns}$

*significant at $\mathrm{P}<.05$ level.

It would appear once again that the more experienced lawyers were significantly more satisfied with their performance than the less experienced lawyers were satisfied with theirs. However the clients again did not show that they noticed any significant difference between the two groups. It would seem that experience leads to greater confidence in one's own abilities but this is not necessarily borne out by the results as perceived by the other party to this transaction, the client. It was therefore interesting to see whether any other differences could be found by analysis of the other forms of assessment carried out.

Table XXII Comparison of Junior and Senior Qualified

$\underline{\text { Solicitors in Total Scores }}$

Variable

Tasks

Techniques

Length of Interview

\section{Means}

2-5 yr

52.2

78.1

36.2

\section{$\mathbf{t}$}

11-20 yr

sig

$56.3 \quad 1.4 \mathrm{~ns}$

85.3

$1.9(.07)$ trend

35.5

$0.1 \mathrm{~ns}$

There was no significant difference in total scores between the two groups on the Tasks assessment by expert assessor but there was a trend towards better performance on Techniques in the more experienced groups. Overall this did not arise out of longer interviews by one group or another since there was no significant difference in the length of their interviews, the means of which were very close at 36.2 minutes and 35.5 minutes. 
The quality of information gained by the two groups was then analysed in further detail.

Table XXIII Comparison of Junior and Senior Qualifiers on

Information

Variable

Client Personal Information

Other Parties

Witnesses

Problem subject categorisation

Events

What client wants

Previous Advice

Legal Proceedings

Next contract

Work to be done by lawyer

Work to be done by client

Advice given
Mean Scores
Group

2-5

11-20

4.1

4.6

$1.2 \mathrm{~ns}$

3.9

3.7

4.0

$0.04 \mathrm{~ns}$

4.9

4.2

4.8

4.4

4.0

3.7

Sig

4.3

4.4

4.2

4.2

4.3

4.2

4.4
5.7

5.0

4.3

4.0

4.7

$3.4 .002 *$

2.0.06trend

$0.6 \mathrm{~ns}$

$0.9 \mathrm{~ns}$

$0.3 \mathrm{~ns}$

$1.1 \mathrm{~ns}$

$1.2 \mathrm{~ns}$

$0.2 \mathrm{~ns}$

4.9

$0.9 \mathrm{~ns}$

On ten out of the twelve scores there were no significant differences showing that experience only appeared to enhance information emerging in an interview in two ways. The more experienced lawyers were better able to pigeon hole their subject matter quickly and see it as falling within a particular problem subject categorisation. They also tended to obtain better information about the events involved in the case. Considering the number of other items on which no significant difference was found it would seem that experience had very little effect on the information obtained as a result of the client interviewing performance of the lawyers studied.

\section{DISCUSSION AND CONCLUSION}

Contrary to intuitive expectation and a prominent view among practitioners, experience largely seemed to enhance competence in a few discrete areas of performance only. In general it did not make much difference to interviewing ability. Improvement in competence appeared to be picked up either at an early stage prior to monitoring in this experiment or not at all.

Practitioners feel that they do inevitably get much better with experience. Such a perception seems to tie in with the much greater confidence the more experienced practitioners showed here in their interviewing performance. Unfortunately that difference is simply not borne out by the objective assessments of their interviewing ability, by clients or expert assessors. Clients could 
not tell any difference at all and there were few headings where experts, blind to the hypothesis being tested, were able to discern any significant differences. ${ }^{60}$

It is conceivably possible that some greater changes in competence had already occurred in the inexperienced group prior to their assessment in this study. This seems unlikely considering the similarity of their profiles and results to the trainees. However, the fact of their involvement in client interviewing by themselves connotes some previous background experience in interviewing even for the trainees studied here. Trainees and solicitors up to 5 years experience were all asked how many interviews they had carried out prior to this study and how many months before the study they had started client interviewing by themselves. They were mostly unable to gauge how many prior interviews there had been, suggesting these were numerous. The number of months since they had first carried out a client interview showed a mean of 76 months with the lowest at 8 months. Even the most inexperienced therefore showed some background in this form of work.

Nevertheless it could well have been expected that experience would show a sequential, gradual progression in competence throughout the years of practice. This was certainly not found. Neither was there a stepwise progression at the Trainee to Qualified stage, nor between solicitors of 2-5 years qualification and those within the 11-20 years range.

All of this contrasts quite markedly with the results of direct training shown elsewhere ${ }^{61}$ and likely to be used in the Law Society's new Legal Practice Course, Professional Skills Course and careful monitoring and supervision in the Training Contract. Experience over time does not appear by itself to turn out vastly better client interviewers, and is a very poor second compared with the results of training. As the literature review suggests unmonitored experience can be a very poor educator. It would therefore seem to be essential that the apprenticeship system of articles ("the training contract") and early qualification should provide careful supervision and monitoring of young lawyers' progress if the full value of experience is to be gained.

60 A reader has suggested that this shows that "experience equals making the same mistakes with greater and greater confidence".

61 See e.g. Sherr, A.H. "Competence and Skill Acquisition in Lawyer Client Interviewing" Warwick University PhD thesis, 1992 Chap.5 (Unpublished) 